\title{
Quercus infectoria Oliv. (Mazı Meșesi) köklerinde oluşan mazılar (Hymenoptera: Cynipidae): İki yeni kayıt
}

\author{
Musa Azmaz ${ }^{\mathrm{a}, *}$ (iD
}

\begin{abstract}
Özet: Batı Palearktik bölge içerisinde mazı arıları çeşitliliği açısından zengin olan Türkiye coğrafyasında son yıllarda yeni türler tanımlanmış ve yeni kayıtlar verilmiştir. Bu çalışmada ise konukçu meşenin köklerinde ve/veya genç toprakaltı dallarında mazı oluşturan bazı türler (Andricus csokai, A. quercusradicis, A. rhyzomae, A. schoenroggei, A. stonei) tespit edilmiştir. Mazı meşesi (Q. infectoria) üzerinden toplanan mazılar içerisinden, A. rhyzomae ve A. schoenroggei türleri Türkiye mazı arıları (Hymenoptera: Cynipidae) faunası için yeni kayıt olarak verilmektedir. Bunun yanı sıra, A. quercusradicis ve A. rhyzomae türleri için yeni bir konukçu meşe kaydı verilirken, A. stonei türünün ise daha önceden Türkiye'den kaydı bilinmesine rağmen ilk kez bu çalışmayla lokasyon kaydı sağlanmaktadır. Tespit edilen beş türün araştırma bölgesindeki (Afyonkarahisar) yayılışı ilk kez yine bu çalışmayla bildirilmektedir.

Anahtar kelimeler: Cynipidae, Mazı, Meşe, Yeni kayıt, Türkiye
\end{abstract}

\section{Cynipid Galls (Hymenoptera: Cynipidae) on Roots of Quercus infectoria Oliv.: Two new records from Turkey}

\begin{abstract}
In recent years, new cynipid species have been described and new records were provided in Turkey where is the most species-rich region in the Western Palearctic region. In this study, some cynipid galls were collected from roots (close to the surface) or branches below the soil surface of the host oak (Andricus csokai, A. quercusradicis, A. rhyzomae, A. schoenroggei, A. stonei). A. rhyzomae and A. schoenroggei among these species are new records for the cynipid (Hymenoptera: Cynipidae) fauna of Turkey. In addition, a new host oak was recorded for A. quercusradicis and A. rhyzomae. Also, the first location record of $A$. stonei was provided with this study although the species previously is known from Turkey. With this study, these five species were reported for the first time for the study area (Afyonkarahisar)
\end{abstract}

Keywords: Cynipidae, Gall, Oak, New record, Turkey

\section{Giriş}

"Mazı (gal)", bitkilerin iletim demetlerini korumak amaciyla yabancı bir organizmayı hapsetmek ve ona besin sağlamak için oluşturdukları anormal büyümelere veya bitkisel urlara denir (Demirsoy, 2006). Mazının oluşumu, dişi mazı arısının ovipozisyonu ile başlamaktadır. Dişi arı konukçu bitkide mazı bölgesini belirler ve yumurtasını bırakır. Zamanla olgunlaşmaya başlayan mazı içinde larvalar gelişmeye başlar. Dişi arının salgıları mazı oluşumunu başlatırken, yumurta ve larvanın salgıları ise mazının gelişimine etki ederek türe özgü yapıda ve şekilde olmasını sağlar. Sonuç olarak olgun hale gelmiş her bir mazı, türler ve nesiller (aseksüel ve seksüel nesil) arası muazzam bir farklılık göstermektedir. Mazılar morfolojik olarak farklı görünse de hepsinin ortak özelliği larva odasına sahip olmasıdır. Sahip olduğu larva odası içerisinde bulunan larva, bitkinin sağlamış olduğu besin dokusu ile beslenerek gelişiir. Gelişen larvalar zamanla ergin arıya dönüşür. Ergin arılar ise mazı içindeki gelişimini tamamlandığında ve uygun çevresel şartlar sağlandığında mazı dokusunu içten yiyerek mazıdan çıkar (Stone vd., 2002; Csóka vd., 2004).
Görüldüğü üzere mazı, böceklerin beslenebileceği ve korunup gelişebileceği bir mikroçevre sağlamaktadır (Price vd., 1986, 1987; Stone ve Schönrogge, 2003). Sonuç olarak bitkiler, mazı oluşturan böceklere karşı kimyasal vb. savunma atakları yapmak yerine onlara gerek duydukları besin kaynaklarını sunarak evrimsel süreçte en iyi yolu bulmuştur (Stone ve Schönrogge, 2003).

Cynipidae Latreille, 1802 familyası üyelerinin çoğunluğu (mazı yerleşimcileri hariç) konukçu bitkilerin mazı oluşturmalarına sebep oldukları için "mazı (gal) arıları" olarak bilinir. Cynipidae familyasının önceleri çeşitli Hymenoptera parazit gruplarını içerdiği düşünülmüştür. Fakat, yapılan çalışmalar sonucunda Cynipidae familyasının "mazı oluşturanlar" ve "mazı yerleşimcileri" olmak üzere iki ana trofik grubu kapsadığı ortaya konmuştur (Melika, 2006). Cynipidae familyası üyeleri, bazı morfolojik özellikleri ile birlikte biyolojisi ve konukçu bitki bilgileri kullanılarak karakterize edilmiş ve 12 tribusa ayrılmıştır. Mazı oluşturan türlerin en önemli konukçu bitkileri: meşeler (Quercus L.), meşelerle yakın akraba diğer Fagaceae cinsleri (Castanea Miller, Castanopsis (D.Don) Spach, Chrysolepis Hjelmq., Lithocarpus Blume ve

\footnotetext{
$\triangle$ a Pamukkale Üniversitesi, Acıpayam Meslek Yüksekokulu, Veterinerlik Bölümü, Laborant \& Veteriner Sağlık Programı, Acıpayam, Denizli, Türkiye

@ * Corresponding author (İletişim yazar1): musazmaz@ pau.edu.tr

$\checkmark \quad$ Received (Geliş tarihi): 01.04.2021, Accepted (Kabul tarihi): 27.04.2021
}

Citation (Atıf): Azmaz, M., 2021. Quercus infectoria Oliv. (Mazı Meşesi) köklerinde oluşan mazılar (Hymenoptera: Cynipidae): İki yeni kayit. Turkish Journal of Forestry, 22(2): 91-96. DOI: $10.18182 /$ tjf.908162 
Notholithocarpus Manos, Cannon \& S.H.Oh) ve güller (Rosa L.). Bunun yanında Asteraceae, Lamiaceae, Rosaceae ve Papaveraceae familyalarına ait bitkiler de mazı arıları için konukçu olabilmektedir. Mazı yerleşimcileri ise, mazı oluşturmayıp yumurtalarını diğer türlerin mazıları içine bırakmaktadır. $\mathrm{Bu}$ türlerin larva gelişimi kendisine ait olmayan mazıların içerisinde olmaktadır (Ronquist vd., 2015; Buffington vd., 2020; Fang vd., 2020).

Cynipini (Cynipidae) tribusu türleri çoğunlukla meşeler ve meşelerle akraba diğer cinsler üzerinde mazı oluşumunu uyardıkları için "meşe mazı arıları" olarak bilinir. Meşe mazı arıları, 45 cinse ait toplam 1085'i aşkın tanımlanmış türleri ile Cynipidae tribusları içerisindeki en zengin taksondur. Bu taksonun üyeleri Holoarktik, Neotropik ve Oryantal bölgelerde dağılım göstermektedir (Ronquist vd., 2015; Buffington vd., 2020). Cynipidae familyası üyeleri pek çok böcek grubunda olduğu gibi konukçu bitkilerine bağımlı olarak yaşar. Bu sebeple meşe mazı arıları, konukçu meşesinin veya meşelerinin dağılım gösterdiğ coğrafyalarda yayılış göstermektedir. $Q$. infectoria (mazı meşesi) meşesi, kayıngiller (Fagaceae) familyasına ait Türkiye, Suriye, İran ve Yunanistan coğrafyasında dağılım gösteren küçük bir ağaç formudur. Bu tür, üzerinde görülebilir büyüklükte Andricus infectorius (Hartig, 1843), A. quercustozae (Bosc, 1792) ve A. sternlichti Bellido, Pujade-Villar \& Melika, 2003 türlerinin mazılarını sıklıkla bulundurmasından dolayı halk arasında "mazı meşesi" adıyla bilinmektedir. Meşe taksonları açısından zengin olan Türkiye coğrafyasında mazı arılarından (Cynipidae) pek çok yeni tür tanımlanmış (Melika ve Stone, 2001; Melika vd., 2004; Dinç vd., 2014; Mutun vd., 2014, 2020; Azmaz ve Katılmış, 2020a, 2020b) ve yeni kayıtlar (Katılmış ve Kıyak, 2008; Mutun ve Dinç, 2011, 2015; Katılmış ve Azmaz, 2015; Azmaz ve Katılmış, 2017) verilmiştir.

Yapılan çalışmalar sonunda, yeni türlerin ve yeni kayıtların sürekli ortaya konması Türkiye Cynipidae faunasının hala tam anlamıyla belirsizliğini koruduğunu göstermektedir. Bu çalışmayla geniş bir dağılıma sahip olan $Q$. infectoria türünün köklerinde veya toprakaltı dallarında mazı oluşturan türler ortaya konarak yeni kayıtlarla birlikte ülke faunasına katkı sağlamak amaçlanmıştır.

\section{Materyal ve yöntem}

Araştırma alanında (Türkiye, Afyonkarahisar, Sandıklı, Otluk köyü, $38^{\circ} 26^{\prime} \mathrm{K}, 29^{\circ} 57^{\prime} \mathrm{D}, 985 \mathrm{~m}$ ) yayılış gösteren mazı meşesinin ( $Q$. infectoria) köklerinden veya toprakaltı dallarından kasım (2019 yılı) ve mart (2020 yılı) aylarında mazılar toplanmıştır. Toplanan mazıların öncelikle çalışma alanında fotoğrafları çekilmiş daha sonra $1 \mathrm{~L}$ hacimli cam kavanozların içine konularak laboratuvara getirilmiştir. İçerisinde mazı bulunan cam kavanozların ağzı, küflenmesini önlemek için gözenekli bir bezin lastikle tutturulmasıyla kapatılmıştır. Laboratuvar koşullarında (25 ${ }^{\circ} \mathrm{C}$ ) mazılarından çıkan ergin arılar \%70'lik etanol içerisine alınmıştır. Ergin arılar önceden kesilen böcek yapıştırma kartlarına etiket bilgileri kaydedilip yapıştırılmıştır. Standart müze materyali haline getirilen örneklerin ve mazıların teşhis işlemleri ilgili kaynaklarda (Melika, 2006; Tavakoli vd., 2008) bulunan teşhis anahtarları ve türlerin tanımlamaları kullanılarak yapılmıştır. Teşhisi yapılan örnekler Pamukkale Üniversitesi, Fen-Edebiyat Fakültesi, Biyoloji Bölümü, Entomoloji Araştırma Laboratuvarı'nda muhafaza edilmektedir. Yeni kayıtlar “*” ile işaretlenmiştir.

\section{Bulgular ve tartışma}

\subsection{Andricus Hartig, 1840}

Andricus cinsi, tür zenginliğinin çok fazla olmasının yanı sıra Holoarktik bölgenin tamamında yayılış gösteren önemli bir taksondur. Andricus türleri, konukçu bitkisi olan meşelerin (Quercus spp.) çeşitli bitki kısımlarında (çiçek, yaprak, kök vb.) mazı oluşturmaktadır (Shachar vd., 2018). Dünya üzerinde yaklaşık 375 türü tanımlanmışken (Buffington vd., 2020) bu türlerden 99 tanesi ülkemizin de içinde konumlandığı Batı Palearktik bölgede yayılış göstermektedir (Pénzes vd., 2018).

\subsubsection{Andricus csokai Melika \& Tavakoli, 2008}

İncelenen materyal: Türkiye, Afyonkarahisar, Sandıklı, Otluk köyü, $38^{\circ} 26^{\prime} \mathrm{K}, 29^{\circ} 57^{\prime} \mathrm{D}$; $985 \mathrm{~m}$; konukçu bitki $Q$. infectoria; mazı toplama tarihi 14.III.2020; laboratuvar koşullarında ergin arı çıkışı 15.III.2020; 7 우.

Biyoloji: Sadece aseksüel nesli bilinmektedir. Aseksüel nesil mazıları, yaz mevsimi başında konukçu meşede görülmeye başlar. Mazı, yer yüzeyine yakın köklerde ve toprakaltı genç dallarda oluşmaktadır. Ergin arılar ise kasım ayının başında mazılarından çıkar (Tavakoli vd., 2008). Bu çalışmada ise mazılar, mart ayında toplanıp laboratuvara getirilmiştir (Şekil 1). Hemen ardından ergin arılar laboratuvar şartlarında mazılarından çıkmıştır.

Konukçu meşeler: $Q$. infectoria (Tavakoli vd., 2008).

Yayılış: İran (Tavakoli vd., 2008) ve Türkiye (Mutun ve Dinç, 2015).

Not: A. csokai aseksüel nesil mazısı, A. quercusradicis aseksüel nesil mazına morfolojik olarak benzemektedir. Fakat, A. csokai aseksüel mazıları daha küçük boyutlarda $(2,5-5,0 \mathrm{~cm})$ olmaktadır.

\subsubsection{Andricus quercusradicis (Fabricius, 1798)}

İncelenen materyal: Türkiye, Afyonkarahisar, Sandıklı, Otluk köyü, $38^{\circ} 26^{\prime} \mathrm{K}, 29^{\circ} 57^{\prime} \mathrm{D}$; $985 \mathrm{~m}$; konukçu bitki $Q$. infectoria; mazı toplama tarihi 14.III.2020; laboratuvar koşullarında ergin arı çıkışı 25.III.2020; 1 \%.

Biyoloji: Hem aseksüel hem de seksüel nesilleri bilinmektedir (Melika, 2006). Seksüel neslin mazıları; konukçu meşenin sürgünlerinde, yaprak saplarında veya yaprak orta damarında oluşmaktadır. Seksüel arılar, ağustoseylül ayları arasında mazılarından çıkar. Bununla birlikte, bazı seksüel arıların bir sonraki yılda mazılarından çıktığı bilinmektedir. Aseksüel neslin mazıları ise yer yüzeyine yakın köklerde veya gövdesi yosunla kaplı ağaçların yer seviyesindeki dallarında oluşmaktadır. Aseksüel arılar, kışı mazı içerisinde geçirdikten sonra mazılarından çıkar ve şubat sonunda konukçu meşenin genç sürgünlerine yumurtalarını bırakır (Melika, 2006). Bu çalışmada ise aseksüel nesil mazıları, mart ayında toplanıp laboratuvara getirilmiştir (Şekil 2). Hemen ardından ergin arılar laboratuvar şartlarında mazılarından çıkmıştır. 


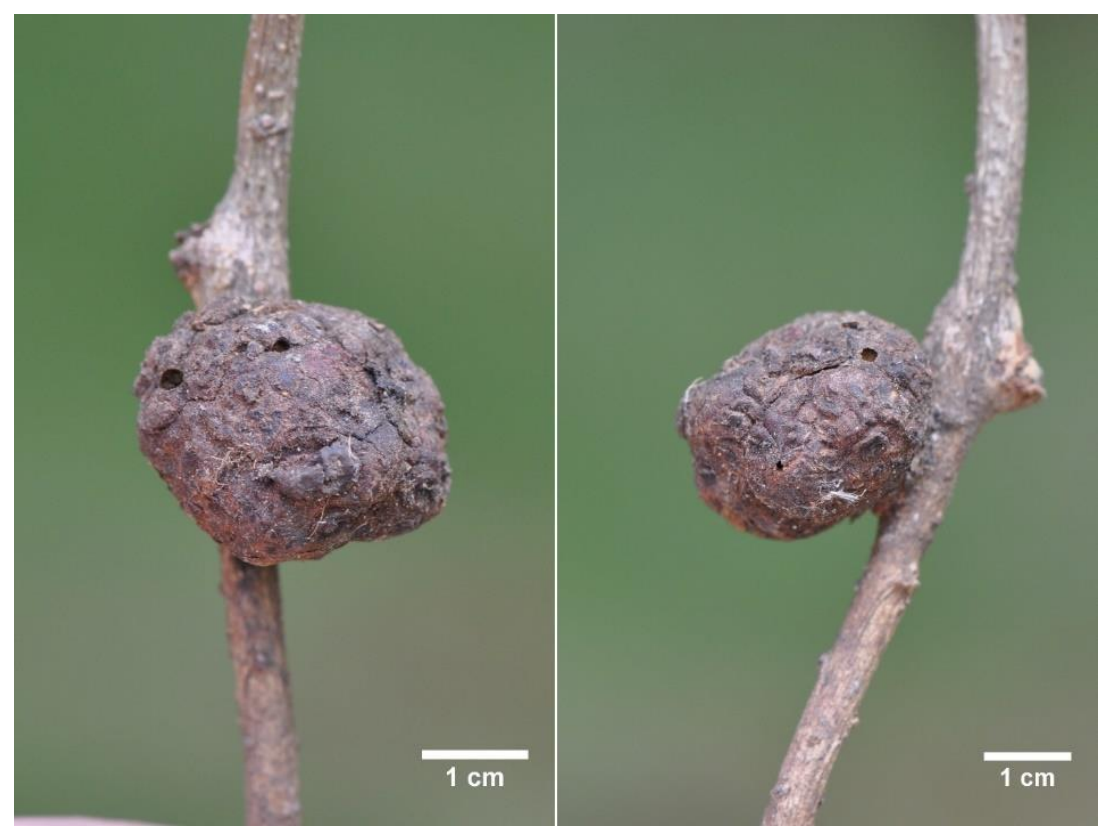

Şekil 1. Andricus csokai aseksüel neslinin mazısı
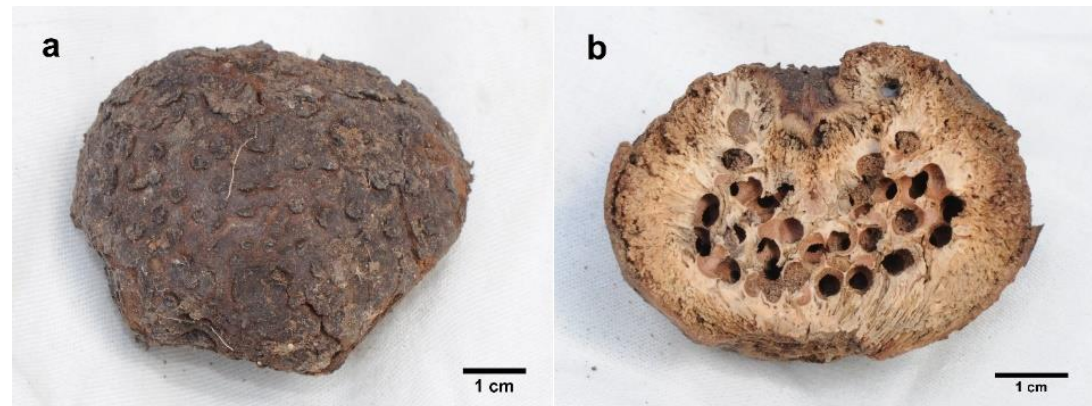

Şekil 2. a) Andricus quercusradicis aseksüel neslinin mazısı; b) Disekte aseksüel mazı

Konukçu meşeler: Aseksüel nesil: $Q$. frainetto (Azmaz ve Katılmış, 2017), $Q$. petraea, $Q$. pubescens, $Q$. robur, $Q$. pyrenaica, $Q$. faginea, $Q$. lusitanica, $Q$. canariensis, $Q$. macranthera, $Q$. ithaburensis, $Q$. coccifera, $Q$. suber (Melika, 2006). Seksüel nesil: Avrupa'da yayılış gösteren meşelerin çoğu üzerinde mazı oluşturur (sıklıkla Q. cerris) (Melika, 2006).

Yayılış: Avrupa kıtası, Rusya (Leningrad bölgesi), Kuzey Afrika, İran, İsrail, Ukrayna, Transkarpatya bölgesi (Melika, 2006) ve Türkiye (Azmaz ve Katılmış, 2017).

Not: Bu çalışmayla ilk kez $Q$. infectoria üzerinde tespit edilmiştir. Aynı zamanda, A. quercusradicis aseksüel nesil mazısı ve A. stonei aseksüel nesil mazısı üst üste gelecek şekilde aynı kök/dal üzerinde birlikte bulunmuştur.

\subsubsection{Andricus rhyzomae (Hartig, 1843)*}

İncelenen materyal: Türkiye, Afyonkarahisar, Sandıklı, Otluk köyü, $38^{\circ} 26^{\prime} \mathrm{K}, 29^{\circ} 57^{\prime} \mathrm{D} ; 985 \mathrm{~m}$; konukçu bitki $Q$. infectoria; mazı toplama tarihi 14.III.2020; laboratuvar koşullarında ergin arı çıkışı 18.V.2020; 4 우.

Biyoloji: Sadece aseksüel nesli bilinmektedir. Aseksüel nesil mazıları, ertesi yılın sonbaharında olgunlaşır. Ergin arılar ise üçüncü yılın mart-nisan aylarında mazının tepesinden çıkar (Melika, 2006). Bu çalışmada ise mazılar, mart ayında toplanıp laboratuvara getirilmiştir (Şekil 3). Ergin arılar laboratuvar şartlarında mayıs ayında mazılarından çıkmıştır.

Konukçu meşeler: Q. petraea, Q. robur (Melika, 2006).

Yayılış: Avrupa kıtası, Rusya (Leningrad bölgesi), Ukrayna, Transkarpatya bölgesi (Melika, 2006) ve Türkiye.

Not: Türün, Türkiye'deki yayılışı ve yeni bir konukçu meşe (Q. infectoria) kaydı ilk kez bu çalışmayla verilmektedir.

\subsubsection{Andricus schoenroggei Melika \& Stone, 2008 *}

İncelenen materyal: Türkiye, Afyonkarahisar, Sandıklı, Otluk köyü, $38^{\circ} 26^{\prime} \mathrm{K}, 29^{\circ} 57^{\prime} \mathrm{D}$; $985 \mathrm{~m}$; konukçu bitki $Q$. infectoria; mazı toplama tarihi 14.III.2020.

Biyoloji: Sadece aseksüel nesli bilinmektedir. Aseksüel nesil mazıları, yaz mevsiminin ilk yarısında gelişmeye başlar. Gelişimini hızlıca tamamlayarak kasım ayı sonunda olgunlaşır. Mazı, yer yüzeyine yakın köklerde ve toprağa gömülü dallar üzerinde oluşmaktadır. Ergin arılar kasımocak ayları arasında mazılardan çıkar (Tavakoli vd., 2008). Bu çalışmada, mazılar mart ayında toplanmıştır (Şekil 4).

Konukçu meşeler: Q. infectoria (Tavakoli vd., 2008). 
Yayılış: İran (Tavakoli vd., 2008) ve Türkiye.

Not: Türün, Türkiye'deki yayılışı ilk kez bu çalışmayla verilmektedir.

\subsubsection{Andricus stonei Melika, Tavakoli \& Sadeghi, 2006}

İncelenen materyal: Türkiye, Afyonkarahisar, Sandıklı, Otluk köyü, $38^{\circ} 26^{\prime} \mathrm{K}, 29^{\circ} 57^{\prime} \mathrm{D} ; 985 \mathrm{~m}$; konukçu bitki $Q$. infectoria; mazı toplama tarihi 29.XI.2019, 14.III.2020; laboratuvar koşullarında ergin arı çıkışı 10.III.2020; 3 우.

Biyoloji: Sadece aseksüel nesli bilinmektedir. Aseksüel nesil mazıları (Şekil 5), yer yüzeyine yakın genç dallarda veya köklerde oluşmaktadır. Mazı, temmuz ayı sonlarında gelişmeye başlar ve ağustos sonu-eylül arasında olgunlaşır. Ergin arılar laboratuvar koşullarında ekim ayının başından ertesi yılın mart ayına kadar çıkmaya devam etmiştir (Azizkhani vd., 2006). Bu çalışmada ise sadece kasım ayında toplanan mazılardan ergin arılar çıkmıştır. Bu arıların çıkışı ertesi yılın mart ayında ve laboratuvar şartlarında gerçekleşmiştir.

Konukçu meşeler: Q. infectoria (Azizkhani vd., 2006).

Yayılış: İran (Azizkhani vd., 2006) ve Türkiye (Mutun vd., 2014).

Not: Türün, Türkiye yayılışı bilinmesine rağmen (Mutun vd., 2014; Azmaz ve Katılmış, 2017) ilk kez bu çalışmayla lokasyon bilgileri verilmiştir. Aynı zamanda, A. stonei aseksüel nesil mazısı ve A. quercusradicis aseksüel nesil mazısı üst üste gelecek şekilde aynı kök/dal üzerinde birlikte bulunmuştur.

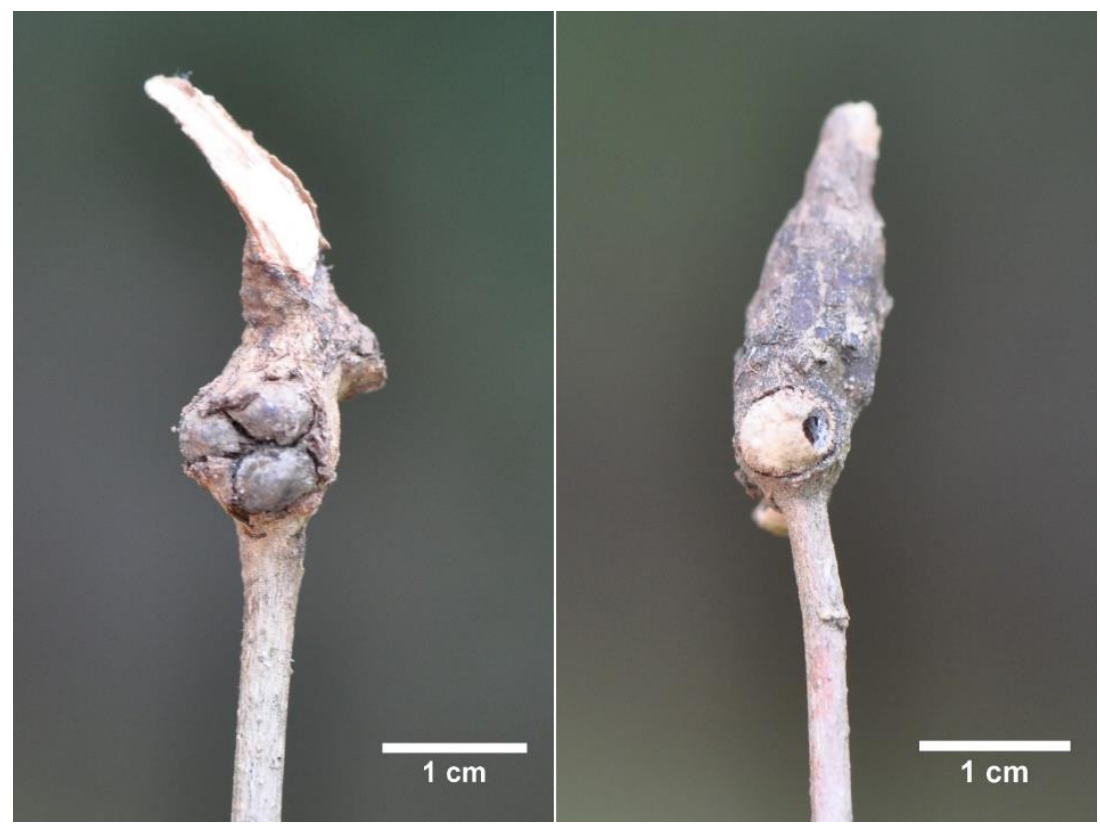

Şekil 3. Andricus rhyzomae aseksüel neslinin mazısı

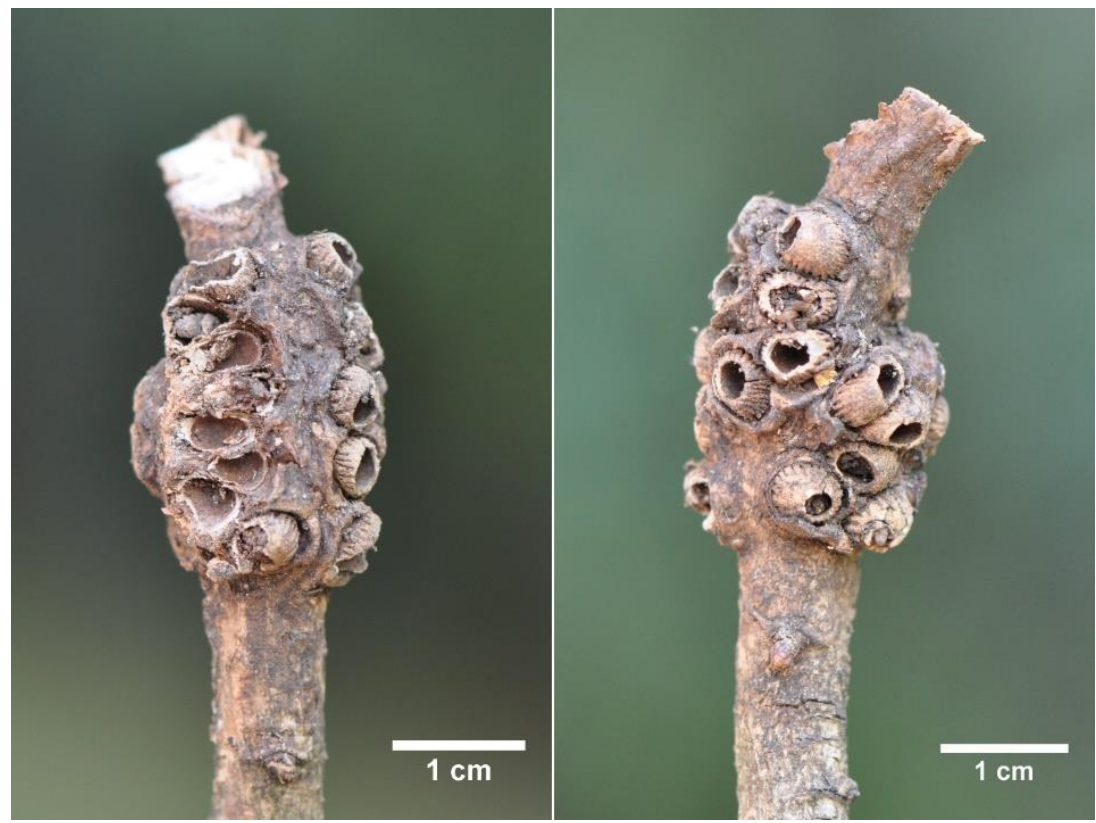

Şekil 4. Andricus schoenroggei aseksüel neslinin mazısı 


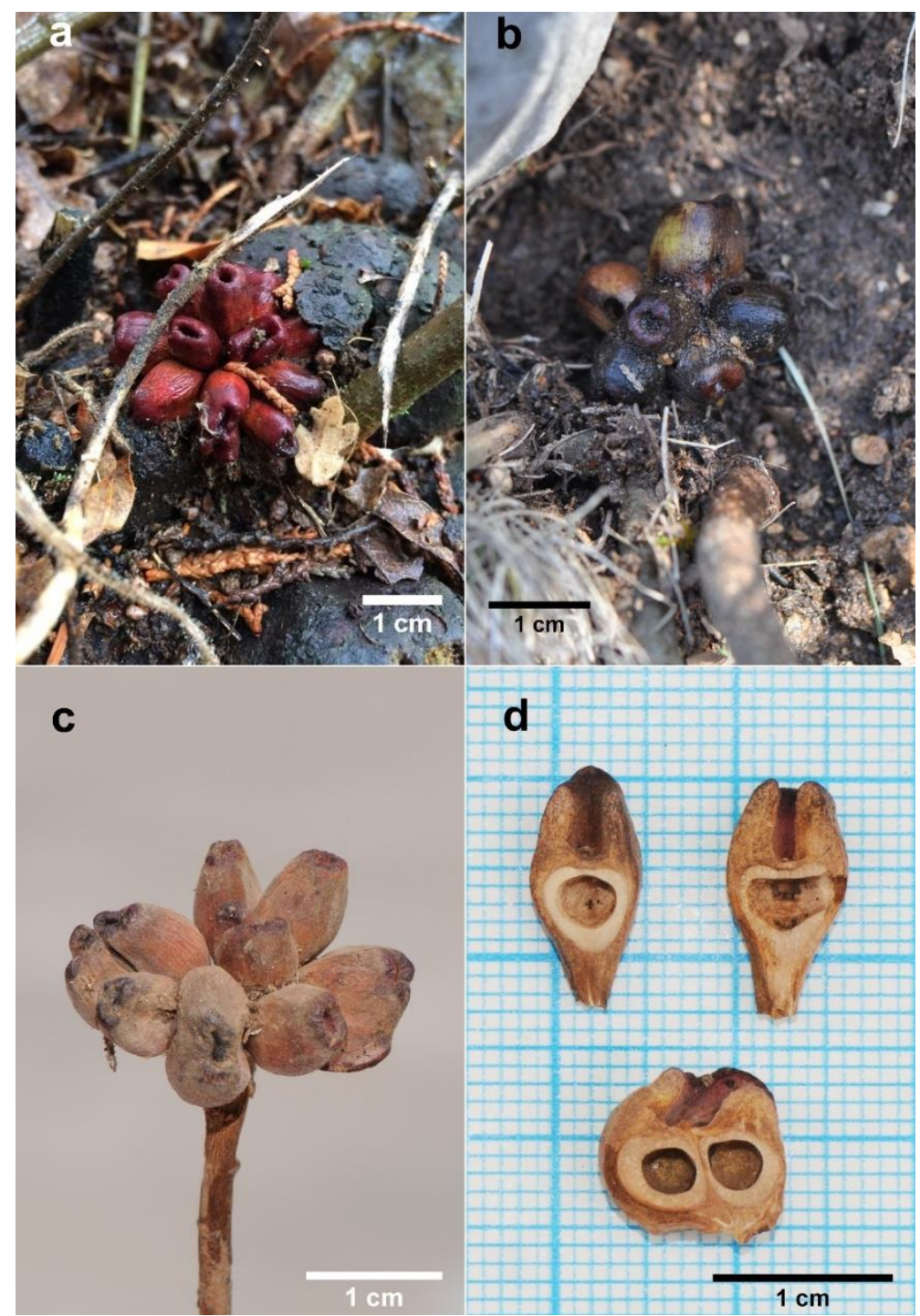

Şekil 5. a-c) Andricus stonei aseksüel neslinin mazısı; d) Disekte aseksüel mazı

\section{Sonuc}

Doğanın ve doğadaki biyoçeşitliliğin korunması dünyanın her yerinde olduğu gibi Türkiye coğrafyasında da her geçen gün önem kazanmaktadır. Türkiye; toprak özellikleri, iklim, bitki örtüsü, farklı jeomorfolojik bölgelere sahip olması, Asya ve Avrupa kıtalarının kesişme noktasında bulunması, üç tarafının denizlerle çevrili olması, üç fitocoğrafik bölgeyi (Avrupa-Sibirya, İran-Turan ve Akdeniz) ve iki Vavilov gen merkezini (Akdeniz ve Yakın Doğu) içermesi gibi sayabileceğimiz pek çok sebeplerden dolayı tarihsel süreçte farklı ekosistemlere sahip olmasıyla Batı Palearktik bölge içerisinde önemli bir konumda bulunmaktadır (Çıplak vd., 1993; Azmaz ve Katılmış, 2017). Bu önemi kazanmasında ekosistemlerinin hayvan ve bitki çeşitliliği açısından zengin olması rol oynamaktadır. $\mathrm{Bu}$ çeşitliliklerin ortaya konması hem Türkiye faunasına hem de dünyadaki biyolojik zenginliklere katkıda bulunulması açısından değerlidir.

Meşeler dahil çoğu Batı Palearktik türlerinin populasyonları büyük oranda Doğu Avrupa, Türkiye, Kafkasya ve İran'a yayılmıştır (Hewitt, 1999). Türkiye genelinde, bazıları endemik olmak üzere toplam 24 meşe taksonu dağılım göstermektedir (Öztürk, 2013). Konukçu bitki çeşitliliğine bağlı olarak mazı arılarının da aynı oranda zengin olacağı yaklaşımı sağlıklı olmamasına rağmen Türkiye coğrafyasında dağılım gösteren mazı arılarının çeşitliliği (Azmaz ve Katılmış, 2017) Batı Palearktik bölgede konumlanan diğer ülke coğrafyalarından daha fazladır (Tavakoli vd., 2021). Bu çalışma sonucunda yapılan katkılar ile Cynipidae familyasını temsil eden tür sayısı artmıştır. Gelecekte farklı bölgelerde yapılacak olan faunistik ve/veya taksonomik çalışmalar ile Türkiye'nin Cynipidae faunasına daha da katkı sağlanacağ 1 düşünülmektedir.

\section{Açıklama}

Çalışmaya olan katkılarından dolayı Sinipidolog (Cynipidologist) Prof. Dr. Yusuf KATILMIŞ’a ve konukçu bitki üzerinden mazıların toplanması yönünde sağladığı yardımlardan dolayı Doç. Dr. Mehmet KARACA'ya teşekkürlerimi sunarım. 


\section{Kaynaklar}

Azizkhani, E., Rasoulian, G.R., Kharazi-Pardel, A., Tavakoli, M., Sadeghi, S.E., Melika, G., Stone, G.N., Atkinson, R., 2006. New species of oak gall wasps from Zagross Mountains of Iran (Hymenoptera: Cynipidae: Cynipini). Folia Entomologica Hungarica, 67: 161-197.

Azmaz, M., Katılmıs, Y., 2020a. A new species of herb gall wasp (Cynipidae, Aulacideini, Aulacidea) from Turkey. Zootaxa, 4747(2): 378-390.

Azmaz, M., Katılmıs, Y., 2020b. A new species of Cynips (Cynipidae: Cynipini) from Turkey. Zoology in the Middle East, 66(3): 232-239.

Azmaz, M., Katılmış, Y., 2017. Updated species list of Cynipidae (Hymenoptera) from Turkey. Zootaxa, 4303(3): 361-378.

Buffington, M.L., Forshage, M., Liljeblad, J., Tang, C.T., van Noort, S., 2020. World Cynipoidea (Hymenoptera): A key to higher-level groups. Insect Systematics and Diversity, 4(4): 169.

Csóka, G., Stone, G.N., Melika, G., 2004. Biology, ecology and evolution of gallinducing cynipidae. In: Biology, Ecology and Evolution of Gall-Inducing Arthropods (Ed: Raman, A., Schaefer, C.W., Withers, T.M.), Science Publishers, Inc. Enfield, USA, New Hampshire, pp. 569-636.

Çıplak, B., Demirsoy, A., Bozcuk, A.N., 1993. Distribution of orthoptera in relation to the Anatolian diagonal in Turkey. Articulata, 8: 1-20.

Demirsoy, A., 2006. Omurgasızlar/Böcekler (Yaşamın Temel Kuralları). Meteksan Yayınları, Meteksan Basımevi, Ankara.

Dinç, S., Mutun, S., Melika, G., 2014. A new species of Andricus Hartig oak gall wasp from Turkey (Hymenoptera: Cynipidae, Cynipini). North-Western Journal of Zoology, 10(1): 122-127.

Fang, Z., Tang, C.T., Nicholls, J.A., Zhu, Y., Xiong, T., Hearn, J., Sinclair, F., Melika, G., Nieves-Aldrey, J.L., Csóka, G., Mikolajczak, K.M., Stone, G.N., Fang, S., 2020. A new genus of Oak gallwasp, Heocynips fang, Nieves-Aldrey, and Melika (Hymenoptera: Cynipidae: Cynipini), from China. Proceedings of the Entomological Society of Washington, 122(4): 787-804.

Hewitt, G.M., 1999. Post-glacial re-colonization of European biota. Biological journal of the Linnean Society, 68: 87-112.

Katılmış, Y., Azmaz, M., 2015. Investigation on the inquilines (Hymenoptera: Cynipidae, Synergini) of oak galls from InnerWestern Anatolia, Turkey. Turkish Journal of Zoology, 39(1): 168-173.

Katılmış, Y., Kıyak, S., 2008. Checklist of Cynipidae of Turkey, with a new genus record. Journal of Natural History, 42(3132): 2161-2167.

Melika, G., Stone, G.N., 2001. A new species of cynipid gall wasp from Turkey (Hymenoptera: Cynipidae). Folia Entomologica Hungarica, 62: 127-131.

Melika, G., 2006. Gall Wasps of Ukraine, Cynipidae. Vestnik Zoologii, 21(1-2): 1-644.
Melika, G., Stone, G.N., Sadeghi, S.E., Pujade-Villar, J., 2004 New species of cynipid gallwasps from Iran and Turkey (Hymenoptera: Cynipidae: Cynipini). Acta Zoologica Academiae Scientiarum Hungaricae, 50(2): 139-151.

Mutun, S., Dinç, S., 2011. Contributions to the gallwasp (Hymenoptera: Cynipidae) fauna of Turkey with one new record. Journal of Applied Biological Sciences, 5(3): 83-85.

Mutun, S., Dinç, S., 2015. Twelve oak gall wasp species (Hymenoptera, Cynipidae) new to the Turkish fauna. Turkish Journal of Zoology, 39(5): 962-964.

Mutun, S., Dinç, S., Melika, G., 2020. Two new species of oak gall wasps from Turkey (Hymenoptera: Cynipidae, Cynipini). Zootaxa, 4890(3): 428-438.

Mutun, S., Dinç, S., Bozsó, M., Melika, G., 2014. Four new species of Andricus Hartig oak gallwasp from Turkey (Hymenoptera: Cynipidae, Cynipini). Zootaxa, 3760(2): 241-259.

Öztürk, Y., 2013. Türkiye Meșeleri Teșhis ve Tanı Kılavuzu. Orman ve Su İşleri Bakanlığı, OGM, Orman Zararlılarıyla Mücadele Dairesi Başkanlığı, Ankara.

Pénzes, Z., Tang, C.T., Stone, G.N., Nicholls, J.A., Schwéger, S., Bozsó, M., Melika, G., 2018. Current status of the oak gallwasp (Hymenoptera: Cynipidae: Cynipini) fauna of the Eastern Palaearctic and Oriental Regions. Zootaxa, 4433(2): 245-289.

Price, P.W., Waring, G.L., Fernandes, G.W., 1986. Hypotheses on the adaptive nature of galls. Proceedings of the Entomological Society of Washington, 88: 361-363.

Price, P.W., Waring, G.L., Fernandes, G.W., 1987. Adaptive nature of insect galls. Environmental Entomology, 16(1): 15-24.

Ronquist, F., Nieves-Aldrey, J.L., Buffington, M.L., Liu, Z., Liljeblad, J., Nylander, J.A.A., 2015. Phylogeny, evolution and classification of gall wasps: The plot thickens. PLoS ONE, 10(5): 1-40.

Shachar, E., Melika, G., Inbar, M., Dorchin, N., 2018. The oak gall wasps of Israel (Hymenoptera, Cynipidae, Cynipini)- diversity, distribution and life history. Zootaxa, 4521(4): 451-498.

Stone, G.N., Schönrogge, K., 2003. The adaptive significance of insect gall morphology. Trends in Ecology \& Evolution, 18(10): 512-522.

Stone, G., Schönrogge, K., Atkinson, R.J., Bellido, D., PujadeVillar, J., 2002. The population biology of oak gall wasps (Hymenoptera: Cynipidae). Annual review of entomology, 47(1): 633-668.

Tavakoli, M., Hosseini-Chegeni, A., Stone, G.N., Sadeghi, S.E., Atkinson, R.J., Melika, G., 2021. The gall wasp fauna of Iran (Hymenoptera: Cynipidae: Cynipinae): species checklist and biogeographical assessment. Zootaxa, 4948(3): 301-335.

Tavakoli, M., Melika, G., Sadeghi, S.E., Pénzes, Z., Assareh, M.A., Atkinson, R., Bechtold, M., Mikó, I., Zargaran, M.R., Aligolizade, D., Barimani, H., Bihari, P., Pirozi, F., Fülöp, D., Somogyi, K., Challis, R., Preuss, S., Nicholls, J., Stone, G.N., 2008. New species of oak gallwasps from Iran (Hymenoptera: Cynipidae: Cynipini). Zootaxa, 1699: 1-64. 